\title{
Preparation and Fracture Behavior of Alumina Platelet Reinforced Alumina-Monazite Composites
}

\author{
Yeong-Kyeun Paek ${ }^{1}$, Ender Suvaci ${ }^{2}$ and Gary L. Messing ${ }^{3}$ \\ ${ }^{1}$ Department of Materials Science and Engineering, Andong National University 388 Songchon-dong, \\ Andong Kyungbuk 760-749, Korea \\ ${ }^{2}$ Department of Ceramic Engineering, Anadolu University, Lki Eylul Kampus, 26470 Eskisehir, Turkey \\ ${ }^{3}$ Department of Materials Science and Engineering, The Pennsylvania State University, University Park, Pennsylvania 16802, USA
}

Fracture behaviors were investigated in the laminated alumina composite ceramics. To improve the mechanical properties of alumina ceramics, templated grain growth (TGG) technique of $\alpha-\mathrm{Al}_{2} \mathrm{O}_{3}$ platelet and $\mathrm{LaPO}_{4}$ as a second phase were introduced. Textured samples were made by the lamination of green tapes through the tape-casting method, while random samples were made through the conventional powder processing method. Green compacts were sintered at $1600^{\circ} \mathrm{C}$ for $2 \mathrm{~h}$ in air. Fracture toughness was tested using indentation strength bending (ISB) method. Indentation on the sample surface was produced by Vickers indent at various loads. From the bending test, enhanced fracture toughness was found in the textured composite, compared to the random composite.

(Received June 24, 2002; Accepted October 24, 2002)

Keywords: alumina-monazite composite, textured composite, templated grain growth, alumina platelet

\section{Introduction}

$\mathrm{Al}_{2} \mathrm{O}_{3}$ ceramics has many beneficial as well as unfavorable properties in engineering applications. Especially, its application to structural materials is limited due to its low toughness. Therefore, much investigation to improve its fracture toughness has been made over several decades. Based on the linear fracture mechanics, toughness of a brittle material depends on the microstructure of the material. Conceptually, the fracture toughness of brittle ceramics can thus be improved by a microstructural design. ${ }^{1)}$

Several toughening mechanisms in ceramics and ceramic composites are operating. ${ }^{2-4)}$ These toughening mechanisms are depending on how crack paths are controlled by variant factors. These factors influencing crack propagation are reported as follows: (i) bulk toughness, (ii) grain boundary toughness, (iii) grain size, (iv) grain shape, (v) grain orientation, (vi) grain boundary energy, (vii) coefficient of friction between the grains, and (viii) the magnitude of the residual stress due to thermal expansion anisotropy (TEA). In a brittle material, additional energy is required to propagate a crack by the above factors, and thereby fracture resistance to crack extension is shown.

In ceramic matrix composites (CMCs), several types of second phases, such as particulate, fiber, whisker and platelet, are using as reinforcement materials. Above all, several studies for platelets as a reinforcement material have been done over the last decade. To date, $\mathrm{SiC}$ and $\mathrm{Al}_{2} \mathrm{O}_{3}$ are well known as platelet type materials. ${ }^{5-7)}$ Recently, Messing et al. ${ }^{8-11)}$ extensively investigated templated grain growth (TGG) using $\mathrm{Al}_{2} \mathrm{O}_{3}$ platelets in alumina ceramics. In TGG, these platelet grains grow and consume the matrix grains to yield microstructures with textured grains. Interesting properties similar to single crystals can be obtained through these textured microstructures. They found that textured alumina produced by TGG had improved fracture toughness compared to that of equiaxed, fine grained alumina. ${ }^{9)}$ But they did not in- vestigate what mechanism operated to enhance the fracture toughness in the textured alumina.

A few years ago, Morgan and Marshall, ${ }^{12)}$ and Mawdsley et $a l .{ }^{13)}$ have studied damage-tolerant alumina ceramic matrix composites, in which crack deflection and delamination occurred between the alumina matrix and reinforcement material during fracture, by placing $\mathrm{LaPO}_{4}$ (monazite) as an weak interphase to promote debonding between the matrix and reinforcement. From their results, $\mathrm{LaPO}_{4} / \mathrm{Al}_{2} \mathrm{O}_{3}$ interface is sufficiently weak to promote debonding. In plateletreinforced materials, fracture toughness can be improved by several mechanisms: (i) pull-out of platelets from the matrix, (ii) crack bridging, (iii) debonding at platelet/matrix interface, (iv) crack deflection, (v) load transfer and so on. ${ }^{5}$ )

In the present work, multi-toughening effect was thus sought for increasing fracture toughness of alumina ceramics by introducing TGG growth and $\mathrm{LaPO}_{4}$ of particulate type as a second phase. The microstructure was designed to become the structure having platelet grains surrounded with $\mathrm{LaPO}_{4}$ particles, to enhance the crack deflection effect of the platelet grains. The $\mathrm{LaPO}_{4}$ particles placed on grain boundaries acted as the preferred paths for crack propagation, and thus promoted the intergranular fracture mode. Especially, The present study was focused on the platelet alignment effect on the toughness of alumina ceramics.

\section{Experimental Procedures}

\subsection{Processing \\ 2.1.1 Sample preparation}

To make a textured alumina-monazite composite, tape casting of an alumina slurry was used. The slurry was prepared by mixing high purity $\alpha-\mathrm{Al}_{2} \mathrm{O}_{3}$ (AKP-50 Sumitomo Chemical Co. Ltd., Tokyo, Japan) adding a $\mathrm{LaPO}_{4}$ $\left(25\right.$ mass \%) and anorthite $\left(\mathrm{CaO} \bullet \mathrm{Al}_{2} \mathrm{O}_{3} \bullet 2 \mathrm{SiO}_{2}: 2\right.$ mass\%) as a liquid phase former with toluene. The $\mathrm{LaPO}_{4}$ was converted from a $\mathrm{LaPO}_{4} \bullet x \mathrm{H}_{2} \mathrm{O}$ (Alfa Aesar, Ward Hill, MA01835) af- 
ter calcination at $900^{\circ} \mathrm{C}$ for $2 \mathrm{~h}$. The anorthite powder was prepared by calcining ball-milled $\mathrm{Al}_{2} \mathrm{O}_{3}, \mathrm{CaCO}_{3}$, and $\mathrm{SiO}_{2}$ powder mixture $\left(\mathrm{Al}_{2} \mathrm{O}_{3}: \mathrm{CaO}: \mathrm{SiO}_{2}=1: 1: 2\right.$ molar ratio) at $1450^{\circ} \mathrm{C}$ for $5 \mathrm{~h}$ and crushing in an alumina mortar with a pestle. $\mathrm{CaCO}_{3}$ was used as a precursor of $\mathrm{CaO}$. The slurry was again wet-milled for $36 \mathrm{~h}$ for deagglomeration and uniform mixing. As a binder, a PVB (polyvinyl butyral) solution (B73210, Ferro-MSI Co.) was added into the slurry.

To induce highly textured microstructure by templated grain growth (TGG), hexagonal $\alpha-\mathrm{Al}_{2} \mathrm{O}_{3}$ platelet particles (Pyrofine Platelets, Elf-Atochem, Pierre-Benite Cedex, France), $20-25 \mu \mathrm{m}$ in diameter and $1.5 \mu \mathrm{m}$ thick, were added at 5 mass $\%$ of the total $\alpha-\mathrm{Al}_{2} \mathrm{O}_{3}$. The platelets for TGG were washed prior to mixing by adding 10 mass $\%$ platelets to water with a $\mathrm{pH}=3$ adjusted with a $\mathrm{HNO}_{3}$. The prepared slurry were tape cast on a glass plate at a speed of $5 \mathrm{~cm} / \mathrm{s}$ at a blade height of $300 \mu \mathrm{m}$ and then dried for $24 \mathrm{~h}$ at ambient conditions. The dry tapes were stripped from the glass, cut and laminated at $60^{\circ} \mathrm{C}$ and $30 \mathrm{MPa}$ for $15 \mathrm{~min}$. A binder burnout was performed with slow heating to $400^{\circ} \mathrm{C}$. The laminated samples $\left(\sim 2.5 \mathrm{~mm}\right.$ thick) were sintered at $1600^{\circ} \mathrm{C}$ for $2 \mathrm{~h}$ in air.

To produce an alumina-monazite composite in which the platelets were randomly oriented, a conventional powder processing was used. Both textured and random composites had the same compositions. Details of sample processing steps are described in Fig. 1.

\subsubsection{Characterization}

The bulk densities of the sintered samples were measured using the Archimedes method with deionized water as the immersion medium. Sections of the samples were cut perpendicular to the casting direction and polished to a $1 \mu \mathrm{m}$ finish using standard ceramograhic techniques. The sections were thermally etched at $1500^{\circ} \mathrm{C}$ for $2 \mathrm{~h}$ in air, gold coated and examined by SEM. The texture development of the samples was measured from the ratio of X-ray peak intensities.

\subsection{Mechanical property measurement}

To control flaw sizes on the polished surface of the specimens, a Vickers diamond indenter was used at various loads. The flexural strength was determined by three-point bending method. Test bars with dimension of $2.0 \mathrm{~mm} \times 1.5 \mathrm{~mm} \times$ $25 \mathrm{~mm}$ were polished to $1 \mu \mathrm{m}$ diamond slurry and long edges chamfered. Then, the bars were annealed at $1200^{\circ} \mathrm{C}$ for $30 \mathrm{~min}$ to remove machining stresses. Instantly after indentation, a drop of silicone oil was placed on the indentation to minimize environmentally assisted subcritical crack growth before strength test. Flexural strength measurement was carried by universal test machine (Hounsfield, H10KS) with $20 \mathrm{~mm}$ span at room temperature. The crosshead speed was $5 \mathrm{~mm} / \mathrm{min}$.

Fracture toughness, $K_{\text {IC }}$, was calculated using the following equation:

$$
K_{\mathrm{IC}}=\xi(E / H)^{1 / 8}\left(\sigma_{\mathrm{f}} P^{1 / 3}\right)^{3 / 4}
$$

where $\xi$ is the geometrical constant of $0.59 ;{ }^{1)} E$ is Young's modulus; $H$ hardness; $\sigma_{\mathrm{f}}$ fracture strength, and $P$ the indentation load. For this calculation, we used $E_{\text {alumina }}=400 \mathrm{GPa},{ }^{13}$ ) $\left.E_{\text {monazite }}=133 \mathrm{GPa},{ }^{13}\right)$ and $E_{\text {composite }}=345 \mathrm{GPa}$. The (b)
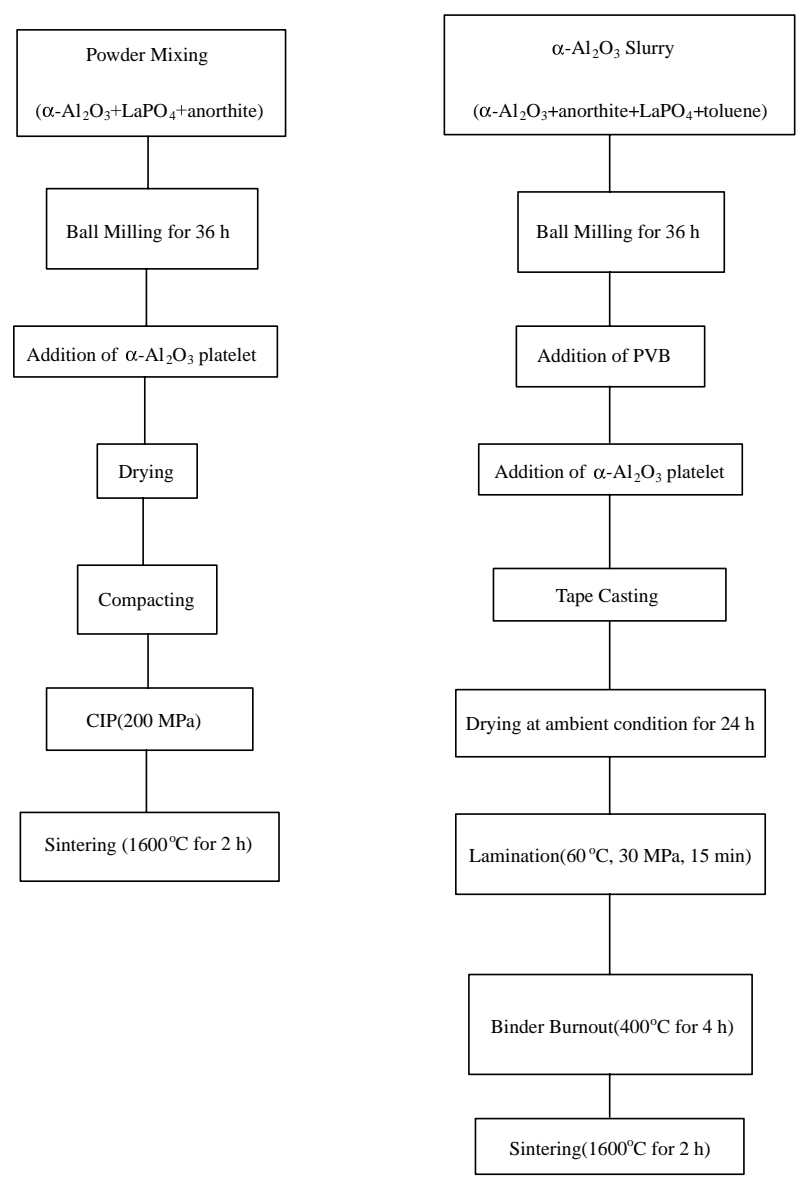

Fig. 1 Processing steps for (a) random and (b) textured alumina-monazite composites.

Young's modulus of this composite was calculated by the rule of mixture. For simplicity in the calculation of the Young's modulus, anorthite amount was neglected, because we do not want to know the exact toughness value but relative comparison between random and textured samples.

\section{Results and Discussion}

\subsection{Microstructure}

Figure 2 shows backscattered SEM microstructures of alumina-monazite composites with templated grain particles. $\alpha$-alumina platelet of $20-25 \mu \mathrm{m}$ in diameter and $5 \mu \mathrm{m}$ thick was used as a precursor of templated grain. The compositions of both samples are the identical as 5 mass $\%$ templates, 25 mass $\%$ monazite, 2 mass $\%$ anorthite, and the remnant alumina. The anorthite as a liquid phase former acts as an activator of densification and templated grain growth (TGG) such as other liquid phase former at sintering temperature. ${ }^{8-11)}$ Also, monazite was introduced as a weak interphase to cause cracks to propagate intergranularly during fracture, based on the results of the previous researchers. ${ }^{12,13)}$ In Fig. 2, white phase is monazite.

The densities of two samples measured by the Archimedes method were the same as nearly 3.80. The value seems to correspond to over $92 \%$ of theoretical density (TD), using the rule of mixture. Despite over $92 \%$ TD, much porosity was found in the Fig. 2. This seems to be caused by se- 

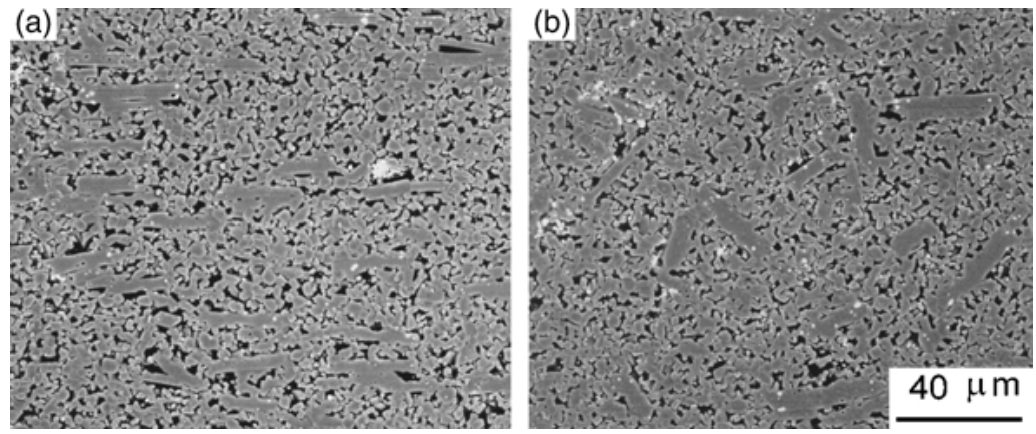

Fig. 2 SEM (backscattered) micrographs of alumina-monazite TGG samples with 5 mass $\%$ templates, 25 mass $\%$ monazites, and 2 mass \% anorthites: (a) textured sample; (b) random sample sintered at $1600^{\circ} \mathrm{C}$ for $2 \mathrm{~h}$ in air. Thermal-etched at $1500^{\circ} \mathrm{C}$ for $2 \mathrm{~h}$ in air. White phase is monazite.

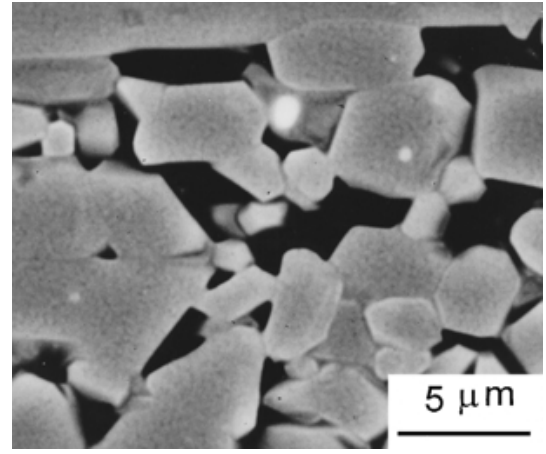

Fig. 3 SEM (backscattered) micrograph showing heavy grain pullout at higher magnification of Fig. 2.

vere grain pull-out during polishing and thermal etching, because the monazite supplied the weak interphase. The fact was supported by the microstructure at higher magnification, as shown in Fig. 3.

In the case of tape-cast sample, as shown in Fig. 2(a), platelet particles are well aligned in the matrix grains, while the sample produced by conventional powder processing shows randomly oriented platelet particles in the matrix grains, as seen in Fig. 2(b). The morphological texture examined by SEM is supported by the X-ray analysis., 10,11) Figure 4 shows X-ray diffraction pattern obtained from textured and random alumina-monazite composites as sintered. Comparing the intensity of several peaks between two samples, significant difference in the intensity of $(00 \bullet 12)$ peak $\left(2 \theta=90.7^{\circ}\right)$ was found. The result indicates that the fraction of platelet particles oriented with this surface toward the sample surface increased in the tape-cast sample rather than the random sample.

\subsection{Fracture toughness}

To measure the fracture toughness of both samples, indentation strength bending (ISB) method was used. Indentation on the polished surface was introduced by Vickers indent. As a crack configuration, center crack on the sample plate was used. Figure 5 shows the interaction of propagating crack with the templated platelet particles at $98 \mathrm{~N}$ load. White phase is monazite. The monazite is supplying the preferred crack path to induce intergranular fracture mode on the alumina grain boundaries. This indicates that the monazite phase is sufficiently weak to act as a path of propagating crack, con-

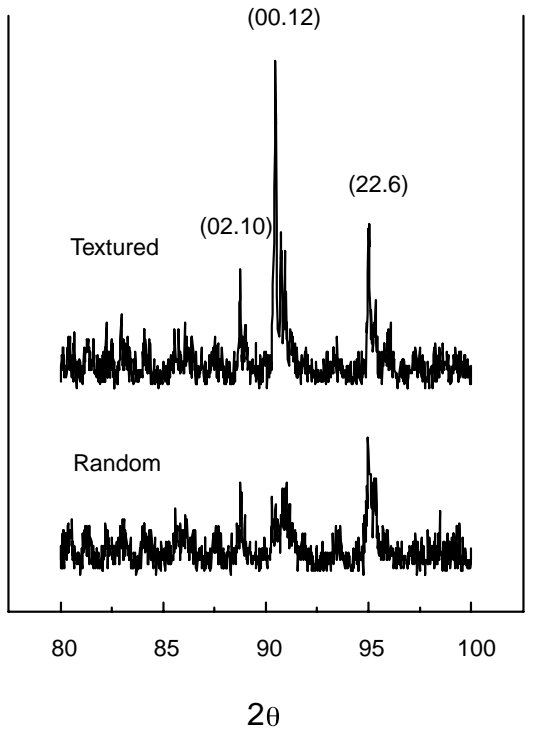

Fig. 4 X-ray diffraction patterns for textured and random aluminamonazite composites sintered at $1600^{\circ} \mathrm{C}$ for $2 \mathrm{~h}$, showing the difference in intensity of $(00 \bullet 12)$ peak between the two samples.

sistent with the previous results. ${ }^{12,13)}$ In the random sample (Fig. 5(a)), platelet particles were with a deviation angle to the propagating crack. In the textured sample, platelet particles were nearly parallel or perpendicular to the propagating crack. Figure 5(b) shows some platelets perpendicular to the propagating crack.

In the both samples, the propagating crack was deflected towards the platelet-matrix interface or cut through the monazite particles. In addition, load transfer on the platelets was found and thereby the middle part of the platelet was fractured. Although the relative fraction of each reinforcing mechanism cannot be determined through the present study, intergranular fracture mode seems to be improved by texturing. The relative difference in the operating toughening mechanism for the two samples, thus, appears to lead to the toughness difference between the textured and random sample.

Fracture toughness and strength data measured by ISB method at various loads were summarized in Table 1, including the hardness data obtained through Vickers indentation. Each data was averaged from three specimens. Fracture toughness $(T)$ of textured sample is always higher than that of random sample at various loads, though the difference is of small significance. Besides, flexural strength $\left(\sigma_{\mathrm{f}}\right)$ increased 

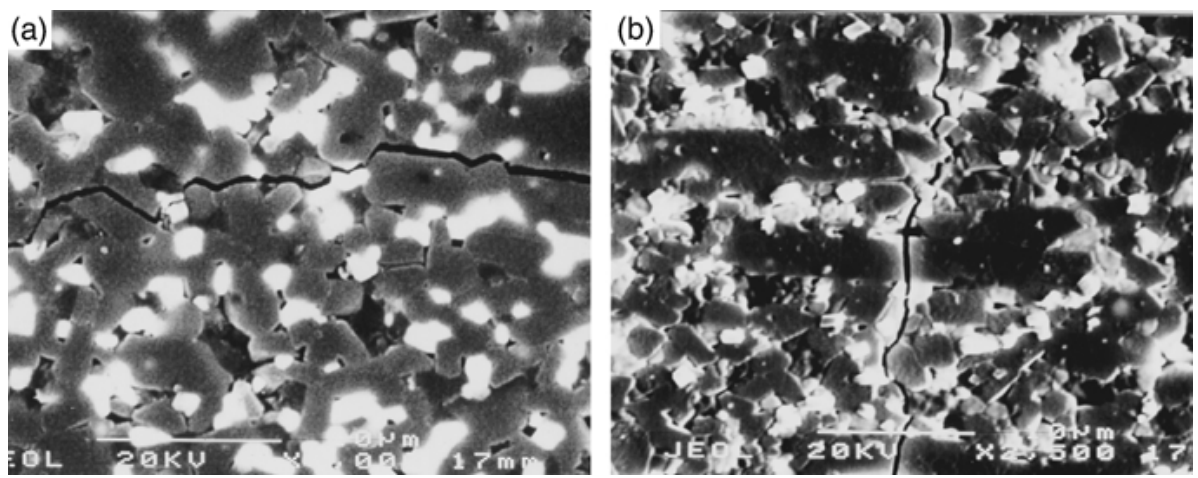

Fig. 5 SEM (backscattered) micrograph showing typical crack propagation in (a) random $(\times 3000)$; (b) textured $(\times 2500)$ alumina-monazite TGG samples (unetched) at $98 \mathrm{~N}$ load. White phase is $\mathrm{LaPO}_{4}$.

Table 1 Fracture toughness $(T)$ and strength $\left(\sigma_{\mathrm{f}}\right)$ measured by ISB method and hardness data.

\begin{tabular}{lccccccc}
\hline \multirow{2}{*}{$\begin{array}{l}\text { Load } \\
\text { Sample }\end{array}$} & \multicolumn{2}{c}{$9.8 \mathrm{~N}$} & \multicolumn{2}{c}{$49 \mathrm{~N}$} & \multicolumn{2}{c}{$98 \mathrm{~N}$} & \multirow{2}{*}{ Hardness } \\
\cline { 2 - 6 } & $T$ & $\sigma_{\mathrm{f}}$ & $T$ & $\sigma_{\mathrm{f}}$ & $T$ & $\sigma_{\mathrm{f}}$ & \\
\hline Random & 3.11 & 229 & 3.55 & 160 & 3.18 & 110 & 8.95 \\
Texutred & 3.16 & 228 & 3.62 & 160 & 3.48 & 120 & 7.70 \\
\hline
\end{tabular}

${ }^{*} T\left(\mathrm{MPa} \bullet \mathrm{m}^{1 / 2}\right), \sigma_{\mathrm{f}}(\mathrm{MPa}) ; \operatorname{Hardness}(\mathrm{GPa})$

** Density of random sample: $3.799 \mathrm{Mg} / \mathrm{m}^{3}$; Density of textured sample: $3.813 \mathrm{Mg} / \mathrm{m}^{3}$

by texturing of platelet particles at $98 \mathrm{~N}$ load. Because mechanical properties are largely dependent on the porosity of specimen, texturing effect on the mechanical properties must be compared at the same porosity condition for the textured and random sample. In this research, the densities of two samples were nearly the same, as seen in Table 1. It is thus believed that the increase in the degree of the intergranular mode by texturing is responsible for the results.

\section{Conclusions}

Platelet alignment effect on the fracture toughness was investigated in the alumina-monazite composite. TGG growth technique of $\alpha-\mathrm{Al}_{2} \mathrm{O}_{3}$ platelets was applied to improve the fracture toughness of alumina ceramics. In addition, $\mathrm{LaPO}_{4}$ of particulate type was added to alumina matrix to enhance intergranular fracture mode or the degree of crack deflection of platelet particles. From the present results, $\mathrm{LaPO}_{4}$ played the role of activator of intergranular fracture mode, and alumina platelet contributed to the toughness enhancement through several toughening mechanisms. The enhancement of fracture toughness by texturing, thus, seems to be attributed to the increment of the intergranular fracture mode through the several toughening mechanisms.

\section{Acknowledgements}

This work was supported by the Korea Science and Engineering Foundation (KOSEF) and Materials Research Institute (MRI) at Penn State University through post-doctoral program. The authors wish to thank Prof. David J. Green for helpful discussion about mechanical property measurement.

\section{REFERENCES}

1) D. J. Green: An introduction to the mechanical properties of ceramics, (Cambridge University Press, 1998) pp. 210-284.

2) D. Kovar and M. J. Readey: J. Am. Ceram. Soc. 77 (1994) 1928-1938.

3) N. P. Padture, S. J. Bennison and H. M. Chan: J. Am. Ceram. Soc. 76 (1993) 2312-2320.

4) F. Lee, M. S. Sandlin and K. J. Bowman: J. Am. Ceram. Soc. 76 (1993) 1793-1800.

5) R. Janssen and K. H. Heussner: Powder Metall. Int. 23 (1991) 242-245.

6) Y. S. Chou and D. J. Green: J. Am. Ceram. Soc. 76 (1993) 1452-1458.

7) L. An, S. Wu, H. M. Chan and M. P. Harmer: J. Mater. Res. 12 (1997) 3300-3306.

8) M. M. Seabaugh, G. L. Messing and M. D. Vaudin: J. Am. Ceram. Soc. 83 (2000) 3109-3116.

9) E. Suvaci and G. L. Messing: J. Am. Ceram. Soc. 83 (2000) 2041-2048.

10) E. Suvaci, M. M. Seabaugh and G. L. Messing: J. of the European Ceram. Soc. 19 (1999) 2465-2474.

11) M. M. Seabaugh, I. H. Kerscht and G. L. Messing: J. Am. Ceram. Soc. 80 (1997) 1181-1188.

12) P. E. Morgan and D. B. Marshall: J. Am. Ceram. Soc. 78 (1995) $1553-$ 1563.

13) J. R. Mawdsley, D. Kovar and J. W. Halloran: J. Am. Ceram. Soc. 83 (2000) 802-808. 